\title{
Use Of Social Media (Face Book) To Promote Health Education: Content Analysis Of Health Pages And User's Perceptions
}

\author{
${ }^{1}$ Adeela Rehman, ${ }^{2}$ Nurazzura Mohamad Diah
}

\begin{abstract}
In today's world of technological advancements, social media is very popular among people of all age group due to its easy and fast access of getting and disseminating all type of information and knowledge. With this consideration, social media is also contributing to promote health education which is very crucial part of every one's life. The present study encompasses the content analysis of the face book pages on health education to explore how and what types of health education benefiting to the users. Ten different face book pages were selected which is promoting health education with different names and contents. The discussion with the followers of these pages was also generated on Facebook to know their opinion regarding the health pages. The analysis depicted that number of face book pages related to health education are based on physical and mental health by focusing providing information related to health habits of eating, and life style. Few pages are also providing spiritual and environmental health to enhance health seeking behaviors. As these facebook pages develops as community and public groups, therefore, numbers of likes and followers shows popularity among the people of all ages who are not only getting benefits but also share more information on health matters. In this way, everyone can get access to various health matters to upgrade their knowledge in terms of health related research articles, books and health related website. The followers who like these pages are having the opinion of getting benefits from these pages in terms of attaining knowledge about healthy living. It is concluded that besides providing the general information to the audience, the health related facebook pages are also promoting research horizon to explore the different avenues of health issues. Based on some discussant's opinion it is recommended to verify the authenticity of the information given before following it as health is very crucial and sensitive matters for the individuals.
\end{abstract}

Keywords: Social Media, Health Education, Facebook

${ }^{1}$ PhD Student, Department of Sociology \&amp; Anthropology KIRKHS, International Islamic University, Malaysia; Lecturer, Department of Gender Studies, Fatima Jinnah Women University, Rawalpindi Pakistan

${ }^{2}$ Associate Professor, Head, Department of Sociology \&amp; Anthropology KIRKHS, International Islamic University, Malaysia 


\section{Introduction}

In today's world of technology, social media is playing a significance role in promoting health education. Through easy access, interaction with largest audience and cheaper accessibility of information, it is getting popularity among people of all ages across the world. Beside only giving information about health matters, social media also enables to interact with health care providers, interprofessional communication in emergency management (Levac \& Sullivan, 2010).

Pew Research Center Publications (2009) estimated that that $61 \%$ youth in USA use social media for health information. Neuhauser \& Kreps (2003) mentioned the reason of relying on social media is due to of its easy availability and frequent usage of internet. Similarly, Farhi (2009) also reported that as the internet is available 24/7 which makes the life easy and accessible to get health education through social media.

It is necessary to expand the appropriate use of social media for health promotion (Brad et al 2014). There must be performance measure indictors to evaluate the authenticity of different pages and sites posted health information. Health organization needs to monitor the growth and progress of such social media to promote healthy environment and accurate information (Judy, 2012).

With the advancement of technology, numerous forms of social media are available and easily accessible. Among all, face book is widely spread and in use of larger population. It is using as largest platform to create awareness on health matters among global population. Park (2011) conducted content analysis of face book pages of health organizations and illustrated the basic information; guidelines, suggestion and planning regarding health life styles are present on health pages. Number of likes and comments indicated that users take interest and fallow the health information and want to know more about it. The suggestion and comments by the users and followers helps the health organization for strategic planning to disseminate more accurate and precise health information.

Social media has varied distinguishing features participation, directness, discussion, as well as making group of people. Feedback mechanisms, such as likes, comments, share, facilitate more participation from users of social media and encourage a discussion among users (Mayfield 2008; Trusoy et al, 2009). Participation enables consumers to interact and understand the health matters by networking with the users to improve their knowledge and familiarize themselves with health matters (Nutbeam, 2000; Kalichman et al., 2002; Guedelman et al 2002). Generally the information posted or shared on the pages is operated by the users of that particular face book page (Gangadharbatla 2011). By considering 
the importance and growth of social media particularly face book, healthcare organization also utilizing its services to promote health matters and invite larger audience to be a part of healthcare decision and planning (Chou et al. 2009).

Currently face book has more than 750 million users and 30 billion pieces of content such as web links, new stories, photo albums, and blog posts etc. It also enables health organizations to use face book applications and allow users to get more information on their health and diet habits (Donohue 2009; Dugan 2010). Beside this, it is also facilitating health insurance agencies to market their products and health programs and to interact with the customers (Terry, 2011).

\subsection{Objectives:}

1. To conduct content analysis of the face book pages disseminating different types of health education.

2. To explore how and what types of health education benefiting to the users.

\subsection{Significance of the study}

On the basis of above evidence of fastest growing and accepting medium of social media, facebook is popular among all age groups who performed different activities on it according to their interest and need. Among all the activities, health education is an important concern which information is frequently shared on facebook through different pages. As health is very critical matter, therefore it is necessary to understand what types of information facebook pages are providing and how users are getting this knowledge for their own health concerns. The study is intended to explore health related facebook pages, their information on types of health concerns, and follower's opinion about these pages.

\section{Research Methodology}

This section comprises of research objectives, research design and procedure adopted to conduct the study.

\subsection{Research Design}

Using qualitative research paradigm, the present study encompasses the content analysis of the face book pages on health education to explore how and what types of health education benefiting to the users. Online group discussion was also generated on facebook to explore the user's perception about the usefulness of health related pages on facebook which they have followed.

\subsection{Sample Size}

Ten different face book pages were randomly selected which is promoting health education with different names and contents. Only those pages were selected which have at least 1000 likes. About 25 followers of health pages participated in discussion and shared their views about using these pages for 
attaining health equation. All of the followers who took part in the discussion were belong to youth age group.

\subsection{Procedure}

At first stage of starting the research, number of health pages on face book was searched by using the researcher's own face book account. Initially 15 pages were downloaded from which 10 were selected having at least 100 likes. In second phase the pages were thoroughly studied to know what type of health information they are sharing, how many people are following these pages and what are their general comments to any information shared on the page. At last stage, the discussion was generated among the followers of the selected page to know their perception about the benefits of these pages for them.

\section{Data Analysis}

The collected data from the content of the pages and from the discussants is described under different themes. Themes were generated according the objective of the study. So the study included thematic analysis to describe and interpret the data.

\section{Theme 1: Types of Health Education}

The content analysis of ten face book pages with different names on health matters indicated that majority of the pages disseminating the information on general health education. This includes, eating habits, patterns for health living, exercise practices, necessary food groups etc. Some of health pages also provide information on medication for general and epidemic diseases and precautionary measures to overcome the illness. Regarding information on food, health eating habits such as time to eat, types of food and nutrition required to body and how to balance the dietary practices. The focus of information was particularly those audience who want to lose their weight in health way. It was also beneficial for youth which usually neglect their health eating habits and prefer junk food as compare to regular organic diet.

The pages named "Health Choices", "Healthy and Natural world", "Health and Fitness Tips", "Health Life body", "Health Eats" and "Health Tips \& Advice" providing bulk of information on food patterns, food choices and food preparation for maintain the health bodies. The basic purpose of providing information through these sites is to create health awareness among the larger audience through these sites

Another facebook page titles "Health Digest" providing blend of health related information such as health diet, and common diseases break through and remedies for treatment. The page also provides research articles on prevalence of different diseases, and physicians' recommendation and guidance to get relief 
from the disease. The articles on avoiding certain types of food in specific health condition, how to lose weight without medication, beauty tips, necessary food to intake etc are the part of this page which are written by health factionaries and researchers. The page mentioned its description as:

"We believe health is wealth, we provide informational health and wellness tips"

The page health life body is also providing research based articles on different matters of maintaining healthy body and preventing illness by adopting healthy food. As the pages given it introduction as:

"Health Life Body is place where we want to create atmosphere full with information's. Our goal is bringing new and original posts about Health Life and Body. Health is one of the most important things. We bring you articles with all information's you need to know about how to stay health, prevent illnesses, cure illnesses. And yes, you will see that in our attempts to keep you informed we always put some twist, making your experience with us more educative and fun".

The content and information of the pages also shows that some health organization prompting their organization website and marketing their products through these face book pages. As almost all of the pages were given the websites links for more details on particular health matters. They also mentioned the website link in the description sheet of the page as shown in below figure:

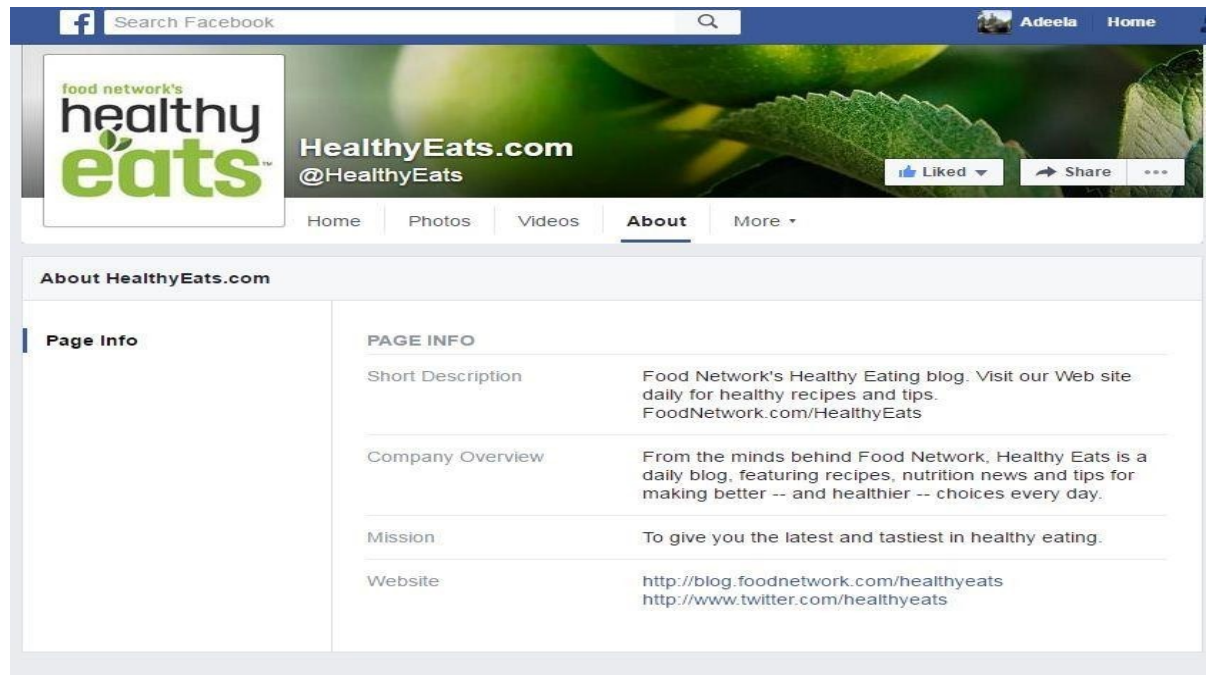




\section{Theme 2: Pictographically Presentation}

By adding images to face book pages attract the audience as well as clarify the content. All the studies pages were glorified with real images of food, exercise patterns and steps, and drinks etc. The pictures explain the contents and make it easier to remember as visual representation keeps in mind for longer period of time. The images also help the audience to be familiar with specific foods in case they have not seen such type of food. Number of food mentioned at face book pages were new to known for the researcher as never heard about that. The name of some items like vegetables, dry fruits, and folk medicines were known but not seen that which helps to identify the required items. The health tips and suggestion were also presented with warning signs and symbols which were eye are catching and kept in mind for long due to amusing and colorful signs and images used. The cover page of the face book pages also presented with certain food and eating items to attract the audience, such as depicted in the following page:

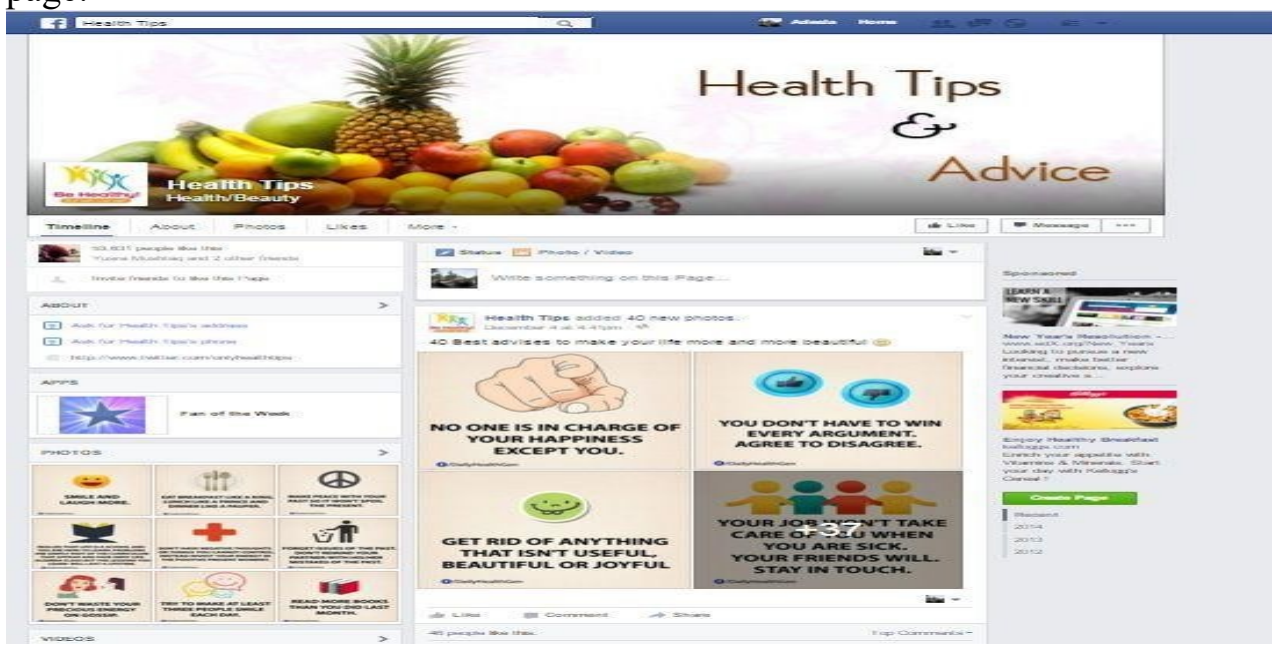

\section{Theme 3: Followers}

All of the studied health pages had more than 6000 likes, an average 1000 comments on different posts and more than 2000 shares. Some of the pages had more than one lack likes and shares. More the likes and shares enhance the marketing of the page, as most of the face book pages on health were designed by health organization which need to promote their company and products. These pages are also using for marking as well as research purpose. Number of content was supported with the research based articles by giving the article links on the post and comments. Hence, the post is become more authentic by attaching 
external links and some additional information which also attracts the audience.

The users who liked the pages, posted different comments and shared the pages were representing the entire world. The users from both the developed and underdeveloped countries as well belongs to any age group, gender, religion and ethnicity were following these pages to gain information on different health matters. Most of the comments are related to extending the information provided at page and also ask the details of the specific food and its usage. The users who had specific knowledge on any topic also added the information in comments.

\section{Theme 4: User's Perception and Experience}

Regarding the usefulness and authenticity of the health information given on different face book pages, a discussion was generated on my own face book page and get feedback from all those friends and their friends who are following health pages on face book. Number of respondents mentioned that the information provided is very useful and they follow it. One of the respondents mentioned as:

"Few reliable ones are highly informative; thus, allowing the right amount of knowledge to flow around us. Additionally, I believe, the traditional way of healing i.e "Totakey" (Folk remedy) which is remarkably making its place in today's scientific era, that seems strange sometime that still face book is providing traditional knowledge"

Another respondent stated;

"Yes I do like these pages, I want to be aware of health issues and these pages are informative and in easy access".

The information provided on health pages are very informative and related to our daily life activities but most of us do not pay much attention to as feel not so important. Likewise mentioned by one of the respondents as:

"Some of the information is very informative such as nutrients. In fact some of the tips are really useful in daily life, I am in the favor of these pages. These pages are really very helpful as I got information on new techniques that are improving our health. These pages also provides up to date information about current new trends occurring around the world so it is very much useful to follow health pages"

Hence the comments on such pages also illustrated that users are following the instruction and applying into their daily life. Yet, the truthfulness and authenticity of the information is required before using any remedy. Because 
all bodies are not same, so the information given as general but with specific health problems need to consider it by consultation with their physicians. Similarly, one respondent stated that:

"These pages are good for just getting awareness but I believe that very few are useful as mostly are not authentic".

Likewise another respondent also mentioned as:

"For me I don't follow these pages because they are not authentic. To just see and like is another matter, but we cannot blindly rely on the information given specially medicines, beauty products, fitness and beauty creams and tablets etc".

So, the responses of the users of health pages are combination of thoughts about the reliability and usefulness of these pages. The users are satisfied with the information and general knowledge of the health concerns available but feel hesitate to follow due to their trustworthiness.

\section{Findings and Discussion}

The study reflects the usage of social media (face book) for disseminating the information and knowledge to promote health education. Due to it easy and cheap access via internet the largest audience is getting benefit from it. As Farhi (2009) also reported that as the internet is available 24/7 which makes the life easy and accessible to get health education through social media.

Currently face book is the rapidly growing and wider medium of communication to promote health education. Most the content of these pages were based on general information related to food and dietary habits for health living. They focused on natural remedies and food for keeping the body health and not be over or under weight. The benefits of having certain food are also mentioned with the details of its effects on body. Many of the pages also highlighted the beautification of body by using food, Vegetables and all other natural ingredients taken from milk and dairy products. It seems to be good for the users to avoid over medication to reduce its side effects as the natural ingredients are more beneficial for maintain the body health and curing for any illness.

It seems larger audience fallow this page to get up to date and authentic information and also like to share the information with their own friends which increases the diverse audience across the globe. The arguments also supported by the earliest study by park (2011) that number of likes and comments indicated that users take interest and fallow the health information and want to know more 
about it. At this matter, the marketing of health products by different companies is so much competitive to reach the largest customers which also put some questions on its reliability and authenticity. As supported by Terry, (2011) that face book also facilitating health insurance agencies to market their products and health programs and to interact with the customers.

\section{Conclusion}

Health related face book pages are providing health education based on physical and mental health by focusing providing information related to health habits of eating, and life style. Few pages are also providing spiritual and environmental health to enhance health seeking behaviors. Numbers of likes and followers shows the popularity of pages among the people of all ages who are not only getting benefits but also share more information on health matters. In this way, everyone can get access to various health matters to upgrade their knowledge in terms of health related research articles, books and health related website. It is also promoting research horizon to explore the different avenues of health issues.

\section{References}

Chou, W. Y. S., Hunt, Y. M., Beckjord, E. B., Moser, R. P., \& Hesse, B. W. (2009). Social media use in the United States: implications for health communication. Journal of medical Internet research, 11(4), e48.

Donohue, Shelley (2009), "Facebook Fitness Application: Fit-ify Health and Fitness Tracker," http://www.examiner.com/fitness-inportland/facebook-fitness- application-fit-ify-health-and-fitness-tracker (accessed October 25, 2010).

Downes, Edward J. \& Sally J. McMillan (2000), "Defining Interactivity," New Media \& Society, 2(2), 157-79.

Dugan, Lauren (2010). Healthy Face book Applications You Should Use to Stay. Farhi, P. The Twitter Explosion. American Journalism Review, 31(3), 26-31, 2009

Freeman, B., \& Chapman, S. (2008). Gone viral? Heard the buzz? A guide for public health practitioners and researchers on how Web 2.0 can subvert advertising restrictions and spread health information. Journal of epidemiology and community health, 62(9), 778-782. 
Gangadharbatla, Harsha (2011), "Social Media and Advertising Theory," in Advertising Theory, S. Rodgers and E. Thorson, eds. Routledge.

Gold, J., Pedrana, A. E., Stoove, M. A., Chang, S., Howard, S., Asselin, J., ... \& Hellard, M. E. (2012). Developing health promotion interventions on social networking sites: recommendations from The Face Space Project. Journal of medical Internet research, 14(1), e30.

Levac, J., \& O'SUlLIVAN, T. (2010). Social Media and Its Use in Health Promotion. Interdisciplinary Journal of Health Sciences, 1(1), 49-57.

Mayfield, A. (2008). What is social media? iCrossing. http://www. icrossing. co. uk/fileadmin/uploads/eBooks/What_is_Social_Media_Crossing_ebook. pdf. Acesso em, 3(11), 2011.

Neiger, B. L., Thackeray, R., Van Wagenen, S. A., Hanson, C. L., West, J. H., Barnes, M. D., \& Fagen, M. C. (2012). Use of social media in health promotion purposes, key performance indicators, and evaluation metrics. Health promotion practice, 13(2), 159-164.

Neuhauser, L., \& Kreps, G. L. (2003). Rethinking communication in the ehealth era. Journal of Health Psychology, 8(1), 7-23.

Newson, Alex, Deryck Houghton, and Justin Patten (2009), Blogging and Other Social Media: Exploiting the Technology and Protecting the Enterprise. Burlington, VT: Gower.

Nutbeam, Don (2000), "Health Literacy as a Public Health Goal: A Challenge for Contemporary Health Education and Communication Strategies into the 21st Century," Health Promotion International, 15(3), 259-67.

Park, H., Rodgers, S., \& Stemmle, J. (2011). Health organizations' use of Facebook for health advertising and promotion. Journal of interactive advertising, 12(1), 62-77.

Pew Research Center (2009). The Shared Search for Health Information on the Internet, Pew Internet \& American Life Project.

Terry, Ken (2011), "Health Insurers Try to 'Humanize' Themselves via 
International Journal of Innovation in Teaching and Learning (IJITL)

Volume I- Issue I (June 2015)

Facebook, Twitter. Retrieved from the web;// http://www.fiercehealthit.com on April 6, 2015. 